\title{
The southward transport of sub-mesoscale lenses of Bass Strait Water in the centre of anti-cyclonic mesoscale eddies
}

\author{
Mark E. Baird ${ }^{1}$ and Ken R. Ridgway ${ }^{2}$ \\ Received 14 December 2011; accepted 23 December 2011; published 27 January 2012.
}

[1] Dense shelf water from Bass Strait, southeast Australia, is presently understood to travel northward along the continental shelf, and disperse eastward into the Tasman Sea. Here we report the unexpected discovery by autonomous gliders of lenses of shelf water $\sim 40 \mathrm{~km}$ in diameter and 200-300 m tall at depth in the center of three $\sim 200 \mathrm{~km}$ diameter anticyclonic eddies. Reanalysis of 2420 vertical profiles off the continental slope in the western Tasman Sea since 1982 found only 3 distinct patches of Bass Strait Water (BSW), all with positive dynamic height anomalies indicative of anticyclones. Through a yet to be understood process, BSW separates from the continental slope and forms a mid-depth lens that aligns vertically with the larger anti-cyclonic mesoscale eddy; and remains at the center of the eddy for $6+$ months as it is advected $700 \mathrm{~km}$ southward. This pathway subducts shelf water into the ocean interior, and provides a link between mesoscale circulation and shelf water transport. The BSW that is captured in anti-cyclones advects south past the east coast of Tasmania, with some moving into the eastern Indian Ocean. Citation: Baird, M. E., and K. R. Ridgway (2012), The southward transport of sub-mesoscale lenses of Bass Strait Water in the centre of anti-cyclonic mesoscale eddies, Geophys. Res. Lett., 39, L02603, doi:10.1029/2011GL050643.

\section{Introduction}

[2] The sinking of dense continental shelf water is an important component of the global thermohaline circulation [Cenedese et al., 2004; Pattiaratchi et al., 2011]. Bass Strait, a 50-70 $\mathrm{m}$ deep channel separating Tasmania from the Australian mainland (Figure 1a) generates dense waters that flow into the Tasman Sea [Godfrey et al., 1980; Cirano and Middleton, 2004]. The water sinks to a depth of $\sim 400 \mathrm{~m}$, and is turned left by the Coriolis force, flowing north along the continental slope (Figure 1b) at speeds of up to $0.5 \mathrm{~m} \mathrm{~s}^{-1}$ [Godfrey et al., 1980; Luick et al., 1994; Middleton and Cirano, 2005] as a geostrophic current along the slope.

[3] The East Australian Current (EAC) is a strong western boundary current that flows along the eastern Australian coast from $20^{\circ} \mathrm{S}$ to approximately $32^{\circ} \mathrm{S}$, and then becomes unstable, spawning anti-cyclonic eddies [Cresswell and Legeckis, 1986]. The eddies move SSW parallel to the continental shelf driven by the tendency for mesoscale eddies to propagate westward [Cushman-Roisin, 1994], and by the

${ }^{1}$ Plant Functional Biology and Climate Change Cluster, Faculty of Science, University of Technology, Sydney, Sydney, New South Wales, Australia.

${ }^{2}$ CSIRO Marine and Atmospheric Research, Hobart, Tasmania, Australia. topographic steering of the Australian coastline. Intriguingly, Scott [1981] found patches of Bass Strait Water (BSW) at depth and relatively undiluted in an EAC anticyclonic eddy $200 \mathrm{~km}$ off the coast.

[4] Under periods of low eddy activity in the EAC, BSW can propagate $1000 \mathrm{~km}$ northward along the continental slope, reaching Newcastle $\left(33^{\circ} \mathrm{S}\right)$ [Tomczak and Tanner, 1989]. Given continuing inflow from Bass Strait, and with the EAC forming a barrier to further northward flow, BSW must spread into the Tasman Sea. Combining sparse observations of the past decade, Villanoy and Tomczak [1991] concluded that BSW was dispersed eastward at approximately the latitude of Bass Strait.

[5] Luick et al. [1994] focused on the BSW transport close to the Bass Strait outflow and found that BSW patches were moving relative to surrounding fluid. One explanation Luick et al. [1994] offered was that BSW patches had obtained rotation as they sunk, forming rotating lenses. Distinct subsurface lenses have been found throughout the world's oceans [McWilliams, 1985; McDowell and Rossby, 1978; Kerr, 1985], often being refered to as submesoscale coherent vortices. The most widely studied of these are the Meddies that originate from the Mediterranean outflow and can propagate $6000 \mathrm{~km}$ across the Atlantic [Nof and Dewar, 1994; Richardson et al., 2000].

[6] Here we report on new observations using autonomous gliders showing that shelf water originating in Bass Strait forms sub-surface lenses at the centre of anti-cyclonic mesoscale eddies in the western Tasman Sea. In contrast to Meddies and other observed sub-mesoscale coherent vortices, the sub-surface lenses we observe in the Tasman Sea appear to be consistently captured by the larger anti-cyclonic mesoscale eddies, and their subsequent transport is completely determined by the path of these eddies.

\section{Methods}

[7] Three deep-water autonomous gliders [Eriksen et al., 2001; Baird et al., 2011] measured temperature, salinity, and oxygen during deployments of 3-6 months duration, in the mesoscale eddy field of the western Tasman Sea in 2009 and 2010 (Figure 1). Processed data were obtained from the Integrated Marine Observing System (IMOS) data portal (http://imos.aodn.org.au/webportal/). The IMOS gliders deployed were: SG516 (Eddy X), SG154 (Eddy Y) and SG152 (Eddy Z). Sections of the glider transects close to the eddies are shown (Figure 2). Along transect distance on the $\mathrm{x}$-axes of Figure 2 is from the starting point of the glider tracks shown in Figure 1. The Eddy X deployment had a degraded oxygen measurement after $800 \mathrm{~km}$ along the transect. 


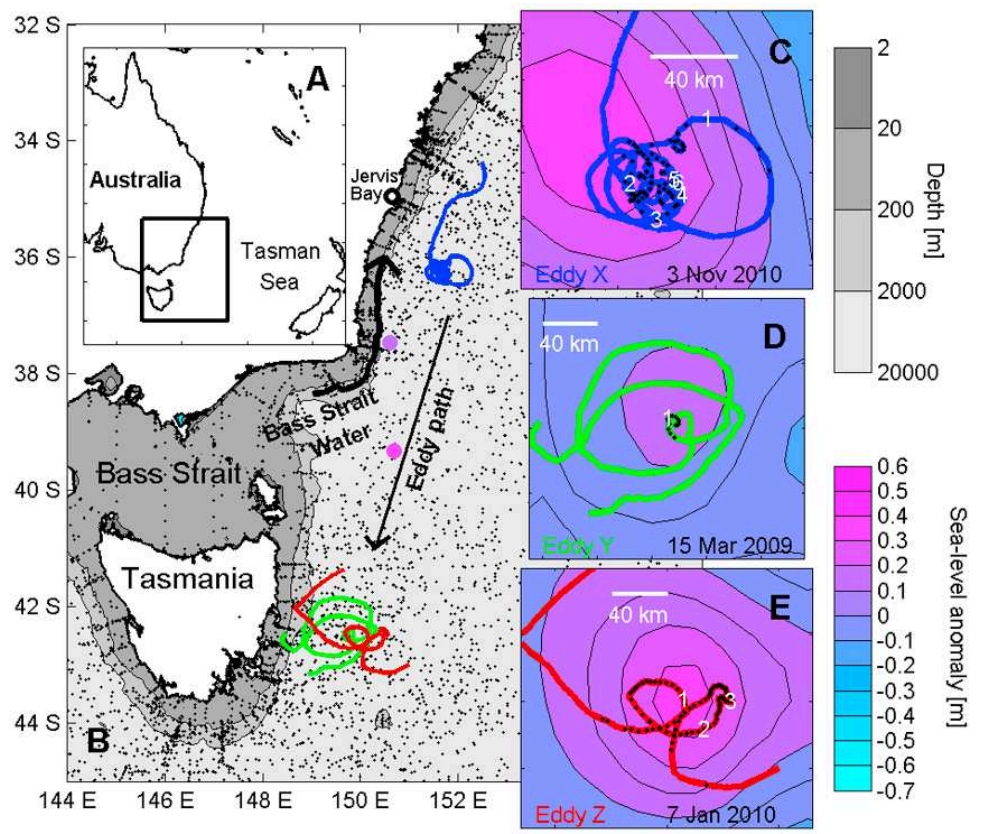

Figure 1. (a) Location of the Tasman Sea. (b) Bathymetry (greyscale) of Bass Strait and the western Tasman Sea and location of observations. The route of BSW as it sinks and spreads northward along the continental slope is shown as a black line. The southward movement of anti-cyclonic eddies is shown as a straight black line. Black dots show the location of historical vertical profiles used in Figure 4. (c-e) Zoom-in on the Eddies X, Y and Z with black dots identifying all locations along the glider track where BSW was identified at mid-depth using criteria in Table 1 . White numbers identify specific times that are labelled in Figure 2. The colorscale shows the surface sea-level anomaly obtained from gridded fields of satellite altimetry. The zoom-ins are individually scaled with a white scalebar given in each panel. Individual vertical profiles containing BSW at $37.46^{\circ} \mathrm{S}, 150.36^{\circ} \mathrm{E}$ and $39.33^{\circ} \mathrm{S}, 150.68^{\circ} \mathrm{E}$ are shown as large dots coloured by sea-level anomaly.

[8] All calculations involving temperature, salinity and potential density use the new international thermodynamic equation of seawater (TEOS-10). The observed quantities, in situ temperature and practical salinity, are converted to conservative temperature, $\theta$, and absolute salinity, $S_{A}$, using TEOS-10 methods [IOC et al., 2010]. The sea level in the
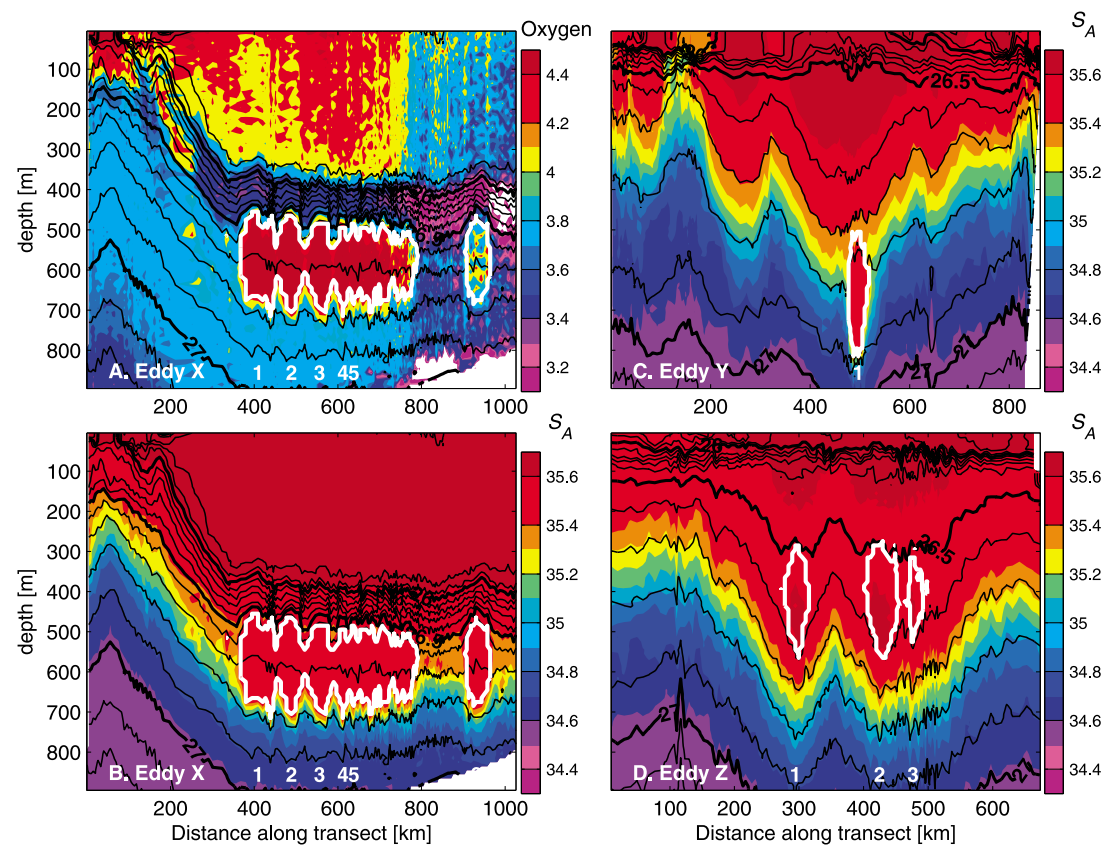

Figure 2. Along glider-track sections of (a) dissolved oxygen (mL/L) for Eddy X, and (b-d) absolute salinity, $S_{A}(\mathrm{~g} / \mathrm{kg})$, for Eddies X, Y and Z respectively. Black lines are potential density, with a contour interval of $0.2 \mathrm{~kg} \mathrm{~m}^{-3}$, with every fifth line thickened. White numbers identify specific times along the track that are geographically located in Figure 1 . White lines identify regions of BSW using criteria in Table 1. 
Table 1. Characteristics of BSW Found at Depth in the Centre of Anti-cyclonic EAC Eddies ${ }^{\mathrm{a}}$

\begin{tabular}{lccc}
\hline & $\begin{array}{c}\text { Absolute } \\
\text { Salinity } \\
{[\mathrm{g} / \mathrm{kg}]}\end{array}$ & $\begin{array}{c}\text { Potential } \\
\text { Density } \\
{\left[\mathrm{kg} \mathrm{m}^{-3}\right]}\end{array}$ & \multicolumn{1}{c}{ Source/Platform } \\
\hline Eddy X & $>35.48$ & $>26.60$ & IMOS seaglider SG516 \\
Eddy Y & $>35.36$ & $>26.75$ & IMOS seaglider SG154 \\
Eddy Z & $>35.61$ & $>26.50$ & IMOS seaglider SG152 \\
Eddy F & $>35.46$ & $>26.40$ & $\begin{array}{l}\text { R.V. Sprightly (SP16/78) } \\
\text { [Scott, 1981] }\end{array}$ \\
Eddy A93 & $>35.45$ & $>26.50$ & $\begin{array}{l}\text { R.V. Southern Surveyor } \\
\text { (SS05/93) }\end{array}$ \\
Eddy A05 & $>35.48$ & $>26.60$ & $\begin{array}{l}\text { Argo float 5900563 } \\
\text { Argo float 5900871 }\end{array}$ \\
Eddy A10 & $>35.46$ & $>26.70$ & a
\end{tabular}

${ }^{\mathrm{a}}$ These criteria are used for identifying BSW along glider transects (Figures 1b-1d), contouring BSW in vertical sections (Figures 2a-2d) and shading BSW in T-S diagrams (Figures 3a-3c).

vicinity of the gliders (Figure 1) was obtained from NASA/ CNES (Jason-1 and 2) and ESA (ENVISAT) and mapped for the Australian region in near-real time with the inclusion of coastal tide gauges [Deng et al., 2010; Ducet et al., 2000].

[9] The CSIRO Atlas of Regional Seas (version 2009a) provides global maps of the annual mean, annual and semiannual components of in situ temperature and practical salinity on a set of standard depths [Ridgway et al., 2002]. A locally-weighted least-squares method is used to generate the mean fields from all CTD stations, bottle casts, and Argo profiles. The interpolation scheme includes terms for seasonal signals, topography and land masses. The 4662 vertical profiles in the western Tasman Sea $\left(32.5-43.5^{\circ} \mathrm{S}, 148\right.$ $155^{\circ} \mathrm{E}$ ) between 10 July 1982 and 7 September 2011 were further analysed for the presence of Bass Strait Water.

\section{Observations}

[10] Mid-depth temperature, salinity and oxygen anomalies were found at the centre of each of the three anti- cyclonic eddies that the gliders crossed. The northern-most anti-cyclone, Eddy X, was centred $200 \mathrm{~km}$ southeast of Jervis Bay (Figures $1 \mathrm{~b}$ and 1c). The glider entered the eddy from the north and was steered at $\sim 0.25 \mathrm{~m} \mathrm{~s}^{-1}$ radiallyinwards, resulting in multiple laps of the eddy close to the centre (Figure 1c).

[11] The glider entered Eddy X between 200 and $350 \mathrm{~km}$ along its transect. Oxygen (Figure 2a), salinity (Figure 2b) and potential density (black lines in Figures 2a and $2 \mathrm{~b}$ ) sections show mid-depth anomalies between 450 and $700 \mathrm{~m}$. The geographical location of all the anomalies are identified by black dots along the blue transect (Figure 1c), and were close to the centre of the eddy as determined by satellite altimetry. The multiple lenses in Figures $2 \mathrm{a}$ and $2 \mathrm{~b}$ represent several entries to, and exits from, the one lens at the centre of the eddy, as identified by white numbers in Figures 1 and 2 . [12] The anomalously high salinity at depth in Figures 2b2d can be identified as BSW [Boland, 1971; Scott, 1981]. BSW shows as $>1026.6 \mathrm{~kg} \mathrm{~m}^{-3}$ density water with anomalously high salinity (Table 1 , black dots in Figures $3 a-3 c$, white contour in Figures $2 \mathrm{a}-2 \mathrm{~d}$ ), corresponding to water in Bass Strait between June and November (Figure 3d). High oxygen within the lens (Figure 2a) indicates that the water had recently been near the surface - further evidence for a shelf origin.

[13] A further two anti-cyclonic eddies (Eddy Y and Z) were sampled $700 \mathrm{~km}$ south of the Eddy X observations (Figures 1d and 1e), a distance typically traversed by Tasman Sea anti-cyclonic eddies in 6-12 months. Both southern eddies showed the same distinct lens formation (Figures $2 \mathrm{c}$ and 2d) and TS properties (Figure 3). In contrast to Eddy $\mathrm{X}$, in which the lens was still forming and the eddy was advecting south, the BSW lenses in the slower-moving Eddy $\mathrm{Y}$ and $\mathrm{Z}$ are located closer to the altimetry-determined centre (Figures 1d and 1e).

[14] Figure 4 presents the TS data for all high quality vertical profiles observed in the region, split into latitudinal
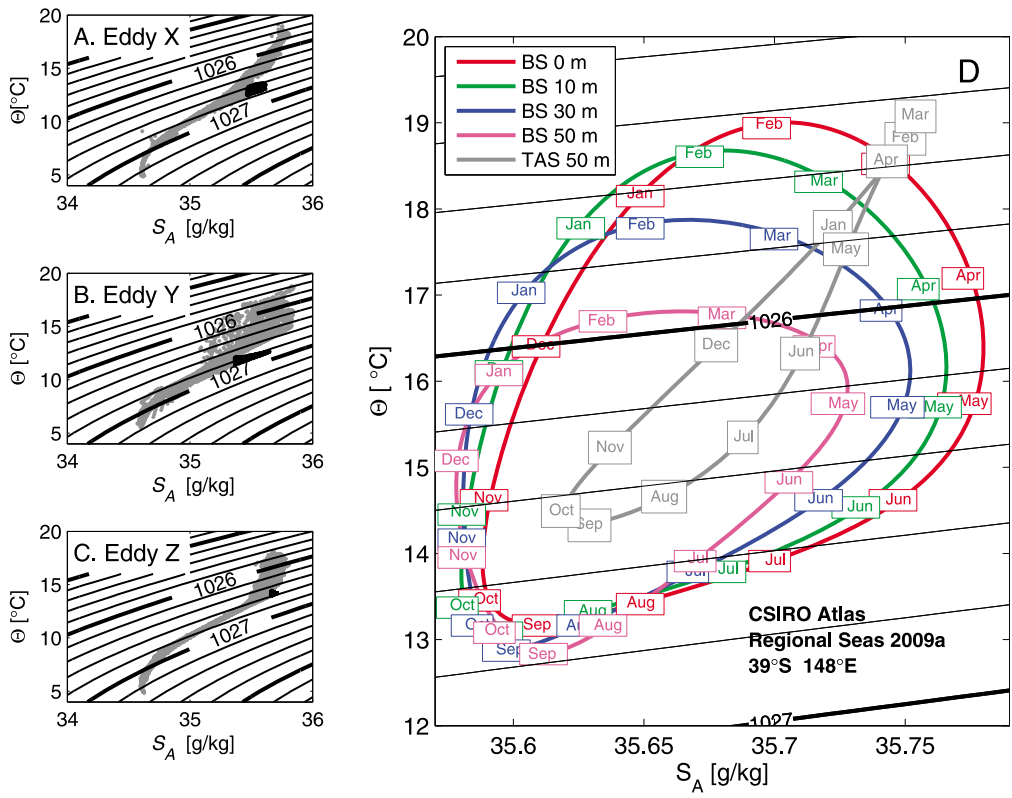

Figure 3. (a-c) TS diagram for the Eddies X, Y, Z. Black dots identify BSW following criteria in Table 1. (d) Climatological TS properties of Bass Strait (BS) at 0, 10, 30 and $50 \mathrm{~m}$, and the adjacent Tasman Sea (TAS) at $50 \mathrm{~m}$ [Ridgway et al., 2002]. Month labels are centred on the 15 th of each month. Line contours are potential density $\left[\mathrm{kg} \mathrm{m}^{-3}\right]$. 

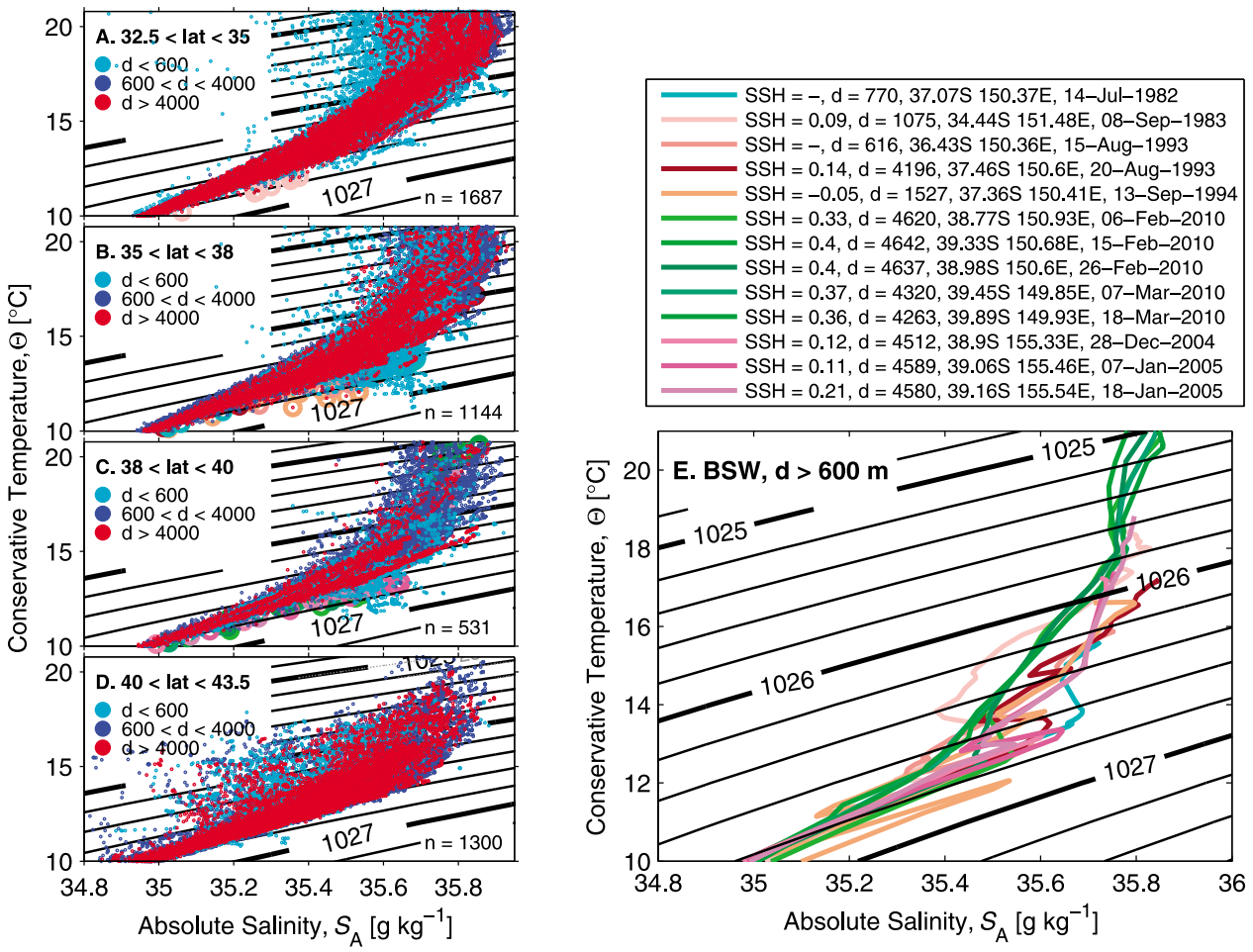

Figure 4. (a-d) TS diagram for historical observation off southeast Australia in latitudinal bands. Color identifies the bottom depth at the location in which the vertical profile was taken. Individual points identified as BSW have a circle around the point with color identifying the vertical profile in which they were found. (e) The vertical profiles containing BSW. The legend gives the sea-level anomaly (calculated by the dynamic height anomaly from its climatology value in CARS 2009a), the bottom depth at the profile location, the location and the sample date. The 5 profiles with BSW in early 2010 (green hues), and the 3 profiles in summer 2004/05 (pink hues) were from Argo floats that resampled the same patch of water in sequential profiles.

bands extending from $145^{\circ} \mathrm{E}$ to $155.5^{\circ} \mathrm{E}$. BSW flows into the Tasman Sea at $38.5^{\circ} \mathrm{S}$ and is evident primarily on the continental shelf and upper slope between $38^{\circ} \mathrm{S}$ and $40^{\circ} \mathrm{S}$ $(\mathrm{d}<600 \mathrm{~m}$, Figure $4 \mathrm{c})$, and between $35^{\circ} \mathrm{S}$ and $38^{\circ} \mathrm{S}(\mathrm{d}<$ $600 \mathrm{~m}$, Figure 4b). Despite 2420 vertical profiles in waters deeper than $2000 \mathrm{~m}$ in the western Tasman Sea (Figures $4 \mathrm{a}-$ $4 d$ ), only 3 patches of BSW were found (Table 1 and Figure 4e), each with a positive dynamic height anomaly relative to climatology (Figure 4, legend), indicative of an anti-cyclone. In contrast, the gliders found BSW in deep water in each deployment. By developing into $40 \mathrm{~km}$ diameter columns at the centre of anti-cyclones, the BSW lenses are poorly resolved by sparse vertical profiles, but are well sampled by vertical profiles of gliders through an eddy centre.

\section{Discussion}

[15] The observation of lenses of BSW in the centre of 7 EAC anti-cyclonic eddies in the western Tasman Sea suggest a robust mechanism for their formation. BSW leaves the Strait and propagates northward taking approximately 7-14 days to reach Jervis Bay. When an anti-cyclonic eddy with an azimuthal velocity near its edge of $\sim 1 \mathrm{~m} \mathrm{~s}^{-1}$ impinges on the shelf, the BSW northward flow encounters strong southward flow. No longer able to propagate north, it is entrained into the edge of the eddy. Once entrained into the eddy, the BSW appears to be attracted to the centre of the larger anti-cyclonic eddy. Vortex-vortex interactions in a rotating flow provide a possible mechanism [Dritschel, 2002]. In a stratified rotating flow, anti-cyclonic vortices of different densities tend to vertically align [Griffiths and Hopfinger, 1987; Nof and Dewar, 1994]. Further, Nof et al. [2002] have shown that gravity currents along shelves can become unstable and break into sub-mesoscale eddies, and this has been speculated for BSW [Luick et al., 1994]. We hypothesize that BSW separates from the shelf, forms a submesoscale vortex, and aligns with the larger EAC anticyclonic eddy. The alignment is stable, and the lens is advected south with the eddy. Observations of the formation process will be necessary to confirm the applicability of these earlier studies to the BSW lens production.

[16] Each year up to 3 anti-cyclones are generated in the EAC [Bowen et al., 2005]. If each of these eddies contain BSW lenses $250 \mathrm{~m}$ high with a diameter of $40 \mathrm{~km}$, a volume of $10^{12} \mathrm{~m}^{3}$, then the southward transport of BSW will be approximately $0.04 \mathrm{~Sv}$. This transport may constitute the entire Bass Strait outflow (as Meddies have been proposed as the principal mechanism for the spread of Mediterranean water [Nof and Dewar, 1994]).

[17] The present understanding in the literature of an eastward dispersal of BSW into the Tasman Sea [Villanoy and Tomczak, 1991], based on calculations of conservative mixing from earlier sparse observations, is not seen in the updated archive. The only BSW found in waters deeper than $2000 \mathrm{~m}$ was at the centre of anti-cyclones. We propose that BSW propagates north along the shelf, and then south at mid-depth in the centre of EAC anti-cyclonic 
eddies. Some EAC anti-cyclones move clockwise around Tasmania, before propagating WNW in the eastern Indian Ocean [Chelton et al., 2011] (Figure S1 in the auxiliary material). ${ }^{1}$ In one case the anti-cyclonic eddy survived for 5 years. The typical path and duration of these eddies may explain the observation of BSW off southwest Australia, some $3000 \mathrm{~km}$ west of Tasmania [Cresswell and Peterson, 1993] (Figure S1).

[18] The presence of shelf water at mid-depth in anticyclones may have ecological consequences. Neutrallybuoyant low-nutrient shelf waters insulate the anti-cyclonic EAC eddy from vertical fluxes of deep nutrients, reducing primary production from what it may otherwise achieve. High oxygen concentrations at mid-depth may encourage deep water pelagic fish populations which are known to be limited by oxygen availability at depth [Koslow et al., 2011].

[19] Lenses of shelf water may be formed in other regions where boundary-current anti-cyclonic eddies interact with continental shelves producing dense water. Western boundaries increase the likelihood of shelf interactions due to the westward propagation of eddies. One such example, a $40 \mathrm{~km}$ diameter lens at 690-840 m depth and density of $1026.7 \mathrm{~kg}$ $\mathrm{m}^{-3}$ at the centre of a Gulf Stream anti-cyclonic eddy [Hallock et al., 1981], is strikingly similar to Eddy Y. We anticipate the new generation of deep ocean gliders will reveal many more lenses of shelf waters at mid-depth in anticyclonic boundary-current eddies, and that the fate of the subducted shelf water will be determined by the path of the eddies.

\section{Summary and Conclusions}

[20] Historical vertical profiles in waters greater than 2000 $\mathrm{m}$ in the western Tasman Sea, now dominated by the quasirandom Argo array, found only 3 three patches of BSW, all associated with anti-cyclonic features. Vertical sections by gliders show that undiluted BSW forms lenses $200+\mathrm{m}$ in height and $\sim 40 \mathrm{~km}$ diameter in the centre of EAC anticyclones in water depths of $2000+\mathrm{m}$. Combined with the observations of Scott [1981], every EAC anti-cyclone south of $35^{\circ} \mathrm{S}$ that we are confident has been sampled at mid-depth at the centre has contained BSW. We therefore conclude that BSW is commonly captured at mid-depth in EAC anticyclonic eddies, and this represents an important sink of BSW that flows into the Tasman Sea. The BSW lenses are then advected with the EAC anti-cyclonic eddy providing a link between shelf water transport and mesoscale processes. Further observational and theoretical work is required to understand the dynamical processes that result in shelf waters forming undiluted vertical-aligned lenses up to $200 \mathrm{~km}$ from the point of separation from the shelf.

[21] Acknowledgments. The gliders were provided by the Australian National Facility for Ocean Gliders (ANFOG), a facility of the Integrated Marine Observing System (IMOS). IMOS is an initiative of the Australian Government being conducted as part of the National Collaborative Research Infrastructure Strategy. Our thanks go to the many scientists, in particular Charitha Pattiaratchi, Iain Suthers, Ben Hollings, Mun Woo, Josh Humphries and Lindsay Macdonald, who's knowhow and dedication made these deployments a reality. KRR was supported by the Australian Climate Change Science Program. The Argo data were collected and made freely available by the International Argo Project and the national programs that contribute to it (http://www.argo.net, http://argo.jcommops.org). Argo is a

\footnotetext{
${ }^{1}$ Auxiliary materials are available in the HTML. doi:10.1029/ 2011 GL050643.
}

pilot program of the Global Ocean Observing System. We thank Madeleine Cahill (CSIRO) for analysing the Australian-region altimeter data, Jeff Dunn (CSIRO) for analysing the archived vertical profiles, and D. Chelton and M. Schlax for freely providing the global database of mesoscale eddies. We thank George Cresswell, Stuart Godfrey, and Peter Oke for insights that much improved this study.

[22] The Editor thanks two anonymous reviewers for their assistance in evaluating this paper.

\section{References}

Baird, M. E., I. M. Suthers, D. A. Griffin, B. Hollings, C. Pattiaratchi, J. D. Everett, M. Roughan, K. Oubelkheir, and M. Doblin (2011), The effect of surface flooding on the physical-biogeochemical dynamics of a warm-core eddy off southeast Australia, Deep Sea Res., Part II, 58, 592-605, doi:10.1016/j.dsr2.2010.06.002.

Boland, F. M. (1971), Temperature-salinity anomalies at depths between $200 \mathrm{~m}$ and $800 \mathrm{~m}$ in the Tasman Sea, Aust. J. Mar. Freshwater Res., 22, 55-62.

Bowen, M. M., J. L. Wilkin, and W. J. Emery (2005), Variability and forcing of the East Australian Current, J. Geophys. Res., 110, C03019, doi: $10.1029 / 2004 J C 002533$.

Cenedese, C. J., J. A. Whitehead, T. A. Ascarelli, and M. Ohiwa (2004), A dense current flowing down a sloping bottom in a rotating fluid, J. Phys. Oceanogr., 34, 188-203.

Chelton, D. B., M. G. Schlax, and R. M. Samelson (2011), Global observations of nonlinear mesoscale eddies, Prog. Oceanogr., 91, 167-216.

Cirano, M., and J. F. Middleton (2004), Aspects of the mean wintertime circulation along Australia's southern shelves: Numerical studies, J. Phys. Oceanogr., 34, 668-684.

Cresswell, G. R., and R. Legeckis (1986), Eddies off southeastern Australia, Deep Sea Res., Part A, 33, 1527-1562.

Cresswell, G. R., and J. L. Peterson (1993), The Leeuwin Current south of Western Australia, Aust. J. Mar. Freshwater Res., 44, 285-303.

Cushman-Roisin, B. (1994), Introduction to Geophysical Fluid Dynamics, Prentice Hall, Englewood Cliffs, N. J.

Deng, X., D. Griffin, K. Ridgway, J. Church, W. Featherstone, N. White, and M. Cahill (2010), Satellite altimetry for geodetic, oceanographic and climate studies in the Australian region, in Coastal Altimetry, edited by S. Vignudelli et al., pp. 472-508, Springer, Berlin.

Dritschel, D. G. (2002), Vortex merger in rotating stratifed flows, J. Fluid Mech., 455, 83-101.

Ducet, N. P., P. Y. L. Traon, and G. Reverdin (2000), Global high-resolution mapping of ocean circulation from TOPEX/Poseidon and ERS-1 and -2, J. Geophys. Res., 105, 19,477-19,498.

Eriksen, C. C., T. J. Osse, R. D. Light, T. Wen, T. W. Lehman, P. L. Sabin, J. W. Ballard, and A. M. Chiodi (2001), Seaglider: A long-range autonomous underwater vehicle for oceanographic research, IEEE J. Oceanic Eng., 26, 424-436.

Godfrey, J. S., I. S. F. Jones, G. H. Maxwell, and B. D. Scott (1980), On the winter cascade from Bass Strait into the Tasman Sea, Aust. J. Mar. Freshwater Res., 31, 275-286.

Griffiths, R. W., and E. J. Hopfinger (1987), Coalescing of geostrophic vortices, J. Fluid Mech., 178, 73-97.

Hallock, Z. R., W. J. Teague, and R. D. Broome (1981), A deep, thick, isopycnal layer within an anticyclonic eddy, J. Phys. Oceanogr., 11, $1674-1677$.

IOC, SCOR, and IAPSO (2010), The international thermodynamic equation of seawater-2010: Calculation and use of thermodynamic properties, Man. Guides 56, 196 pp., UNESCO, Paris.

Kerr, R. A. (1985), Small eddies are mixing the ocean, Science, 230, 793.

Koslow, J. A., R. Goericke, A. Lara-Lopez, and W. Watson (2011), Impact of declining intermediate-water oxygen on deepwater fishes in the California Current, Mar. Ecol. Prog. Ser., 436, 207-218.

Luick, J. L., R. Kase, and M. Tomczak (1994), On the formation and spreading of the Bass Strait cascade, Cont. Shelf Res., 14, 385-399.

McDowell, S. E., and H. T. Rossby (1978), Mediterranean water: An intense mesoscale eddy off the Bahamas, Science, 202, 1085-1087.

McWilliams, C. (1985), Submesoscale, coherent vortices in the ocean, Rev. Geophys., 23, 165-182.

Middleton, J. F., and M. Cirano (2005), Wintertime circulation off southeast Australia: Strong forcing by the East Australian Current, J. Geophys. Res., 110, C12012, doi:10.1029/2004JC002855.

Nof, D., and W. K. Dewar (1994), Alignment of lenses: Laboratory and numerical experiments, Deep Sea Res., Part I, 41, 1207-1229, doi:10.1016/0967-0637(94)90041-8.

Nof, D., N. Paldor, and S. V. Gorder (2002), The Reddy maker, Deep Sea Res., Part I, 49, 1531-1549.

Pattiaratchi, C., B. Hollings, M. Woo, and T. Welhena (2011), Dense shelf water formation along the south-west Australian inner shelf, Geophys. Res. Lett., 38, L10609, doi:10.1029/2011GL046816. 
Richardson, P. L., A. S. Bower, and W. Zenk (2000), A census of meddies tracked by floats, Prog. Oceanogr., 45, 209-250.

Ridgway, K. R., J. R. Dunn, and J. L. Wilkin (2002), Ocean interpolation by four-dimensional least squares-Application to the waters around Australia, J. Atmos. Oceanic Technol., 19, 1357-1375.

Scott, B. D. (1981), Hydrological structure and phytoplankton distribution in the region of a warm-core eddy in the Tasman Sea, Aust. J. Mar. Freshwater Res., 32, 479-492.

Tomczak, M., and E. Tanner (1989), An estimate of Bass Strait Water movement in the western Tasman Sea during the Australian Coastal Experiment, Aust. J. Mar. Freshwater Res., 40, 465-469.
Villanoy, C. L., and M. Tomczak (1991), Influence of Bass Strait water on the Tasman Sea thermocline, Aust. J. Mar. Freshwater Res., 42, $451-464$.

M. E. Baird, Plant Functional Biology and Climate Change Cluster, Faculty of Science, University of Technology, Sydney, PO Box 123, Broadway, Sydney, NSW 2007, Australia. (mark.baird@uts.edu.au)

K. R. Ridgway, CSIRO Marine and Atmospheric Research, GPO Box 1538, Hobart, Tas 7001, Australia. (ken.ridgway@csiro.au) 